Short Communication

\title{
Brain-derived neurotrophic factor blood levels in two models of transient brain ischemia in rats
}

\author{
Miroslav Gottlieb*, Petra Bonova*, Viera Danielisova, Miroslava Nemethova, Jozef Burda \\ and Dasa Cizkova
}

Institute of Neurobiology, Slovak Academy of Sciences, Kosice, Slovak Republic

\begin{abstract}
We monitored possible influence of transient focal and global brain ischemia on BDNF blood level. In both models noticeable fluctuation of BDNF concentration mainly in reperfusion was observed. During the first $90 \mathrm{~min}, \mathrm{BDNF}$ in total blood and in blood cells continuously decreased in both models but plasma BDNF raised at $40 \mathrm{~min}$ and peaked at $90 \mathrm{~min}$ of reperfusion. Our data confirm the impact of transient brain ischemia on BDNF levels in the circulatory system, suggest blood cells as a possible source of BDNF and demonstrate the interdependence of blood compartments and physiological state of an affected organism.
\end{abstract}

Key words: BDNF - Brain — Global ischemia — Focal ischemia - Blood

Since the purification of brain-derived neurotrophic factor (BDNF) in 1982 (Barde et al. 1982), a great deal of evidence has mounted for its central roles in brain development, physiology, and pathology. Aside from its importance in neural development and cell survival, BDNF appears essential to molecular mechanisms of synaptic plasticity. Basic activity-related changes in the central nervous system are thought to depend on BDNF modification of synaptic transmission, especially in the hippocampus and neocortex. Pathologic levels of BDNFdependent synaptic plasticity may contribute to conditions such as epilepsy and chronic pain sensitization, whereas utilization of BDNF role in supporting of neuronal survival and encouraging the growth and differentiation of new neurons and synapses may lead to novel therapeutic options in neurodegenerative diseases and perhaps even in neuropsychiatric disorders (Binder and Scharfman 2004; Binder 2007).

At present, it is well known that BDNF has a relatively important neuroprotective role in either global (Beck et al. 1994) or focal brain ischemia (Schabitz et al. 1997, 2000; Yamashita et al. 1997). Transient global forebrain ischemia as well as focal ischemia induces BDNF mRNA upregulation at the site of injury which seems to correlate with resistance to injury in this

Correspondence to: Miroslav Gottlieb, Institute of Neurobiology, Slovak Academy of Sciences, Soltesovej 4/6, 04001 Kosice, Slovak Republic

E-mail: gottlieb@saske.sk

* Both authors contributed equally to this work area (Tsukahara et al. 1994, 1998; Kokaia et al. 1995). Moreover, the concentration of BDNF after an ischemic attack is not homogenous in the whole brain, but is elevated in regions of higher resistance to ischemic condition (Kokaia et al. 1996).

In addition to the finding that ischemia-reperfusion causes changes in tissue levels of BDNF, it was established that $B D N F$ readily crosses the blood brain barrier (BBB). Serum concentrations correlate directly with brain concentrations therefore plasma studies of BDNF accurately reflect CNS concentrations (Pan et al. 1998; Karege et al. 2002; Enstrom et al. 2008). Moreover, several types of blood cells could be a source of this protein (Braun et al. 1999; Kerschensteiner et al. 1999; Fujimura et al. 2002).

Based on this, we decided to study effects of ischemic conditions on blood levels of BDNF. Specifically, we used two models of transient cerebral ischemia to examine changes of BDNF levels in whole blood, blood cells, and plasma during ischemia and short-term reperfusion.

Experiments were approved by the Institutional Ethical Committee, in accordance with current national legislation. All efforts were made to minimize animal suffering and to reduce the number of animals used. Adult male albino Wistar rats ( $n=4$ for each ischemia model) weighing 270-330 g were fasted overnight before surgery.

During the surgical procedure the rats were anesthetized with halotan (3.5\% initial, $1 \%$ to $1.5 \%$ maintenance during surgery). Transient focal cerebral ischemia was produced by right middle cerebral artery occlusion (MCAO) (Longa 
et al. 1989) for $90 \mathrm{~min}$ followed by $90 \mathrm{~min}$ of reperfusion. Neurological deficit was assessed in each animal on a numerical scale of $0-4$ at 60 min of MCAO and at 1 hour of postischemic reperfusion: 0 , no detectable deficits; 1 , turning of torso and contralateral forelimb when lifted by the tail; 2 , score 1 and decreased resistance to lateral push, leaning to the contralateral side at rest with prominent circling to the left; 3 , score 2 and circling to the contralateral side spontaneously or when rat was held by the tail; 4 , no spontaneous walking and a depressed level of consciousness. Rats with a neurological deficit lower than 2 were excluded from the study.
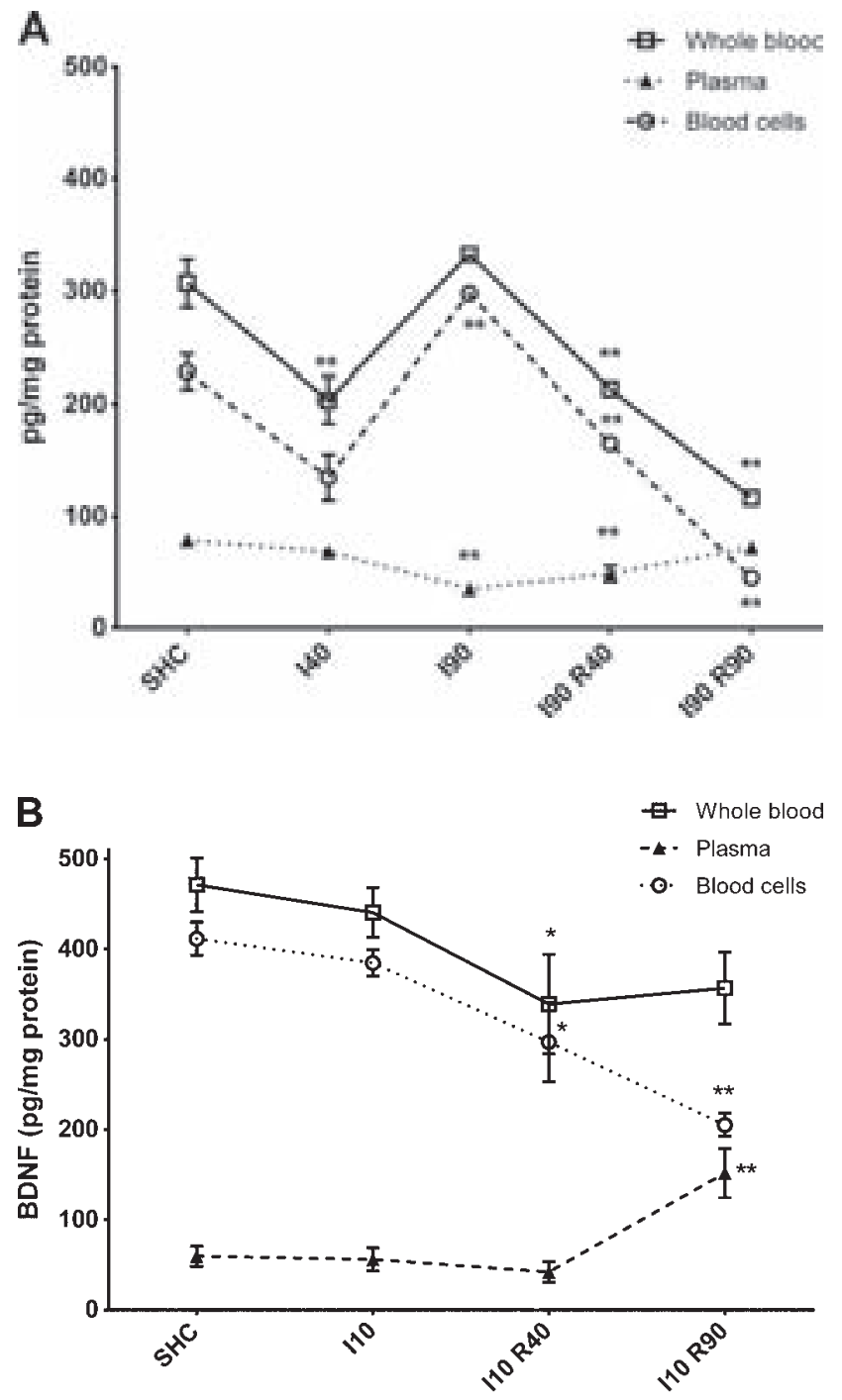

Figure 1. BDNF concentration in whole blood, plasma and blood cells during and after MCAO (A) and after transient global brain ischemia (B). Data are expressed as mean \pm SEM of 4 animals in each group. ${ }^{*} p<0.05,{ }^{* *} p<0.01$. SHC, sham control; I10, I40,I90 - ischemia in minutes; R40, R90 - reperfusion in minutes.
Transient global brain ischemia $(10 \mathrm{~min})$ was induced by four vessel occlusion (4VO) model described previously (Pulsinelli and Brierley 1979). Normothermic conditions (approximately $37^{\circ} \mathrm{C}$ ) were maintained by a feedback-controlled heating lamp and pad. Animals that became unresponsive within $60 \mathrm{~s}$ after clip tightening, lost the righting reflex during bilateral carotid artery occlusion, and showed no seizures during and after ischemia were used for the experiment. Rats survived for 7 days for histological analysis of the extent of CA1 hippocampal neurodegeneration using FluoroJade B staining. Only animals with degeneration of at least $70 \%$ were included in the experiment.

Samples of whole blood were obtained by permanent cannulation of right external jugular vein. The silicone cannula was routed to the surface of neck skin to eliminate repeated anesthetization of animal during the blood collection and to minimalize influence of anesthesia. Sham control sample (SHC) was collected directly before MCAO and $4 \mathrm{VO}$ surgical procedures into heparinized tubes. Test samples were collected 40 and 90 min after ischemia induction in the model of MCAO and at the end of the ischemic insult in the $4 \mathrm{VO}$ model, and at 40 and 90 min of restoration of brain blood circulation. Plasma was obtained by centrifugation $\left(10,000 \times g, 4^{\circ} \mathrm{C}, 10 \mathrm{~min}\right)$ of $150 \mu \mathrm{l}$ of the blood. Whole blood samples were prepared by repeated rapid freezing $\left(10 \mathrm{~min},-20^{\circ} \mathrm{C}\right)$ and defreezing at $37^{\circ} \mathrm{C}$ and finally were centrifuged at $10,000 \times g\left(4^{\circ} \mathrm{C}, 10 \mathrm{~min}\right)$. Supernatant of whole blood lysates as well as samples of plasma were stored at $-80^{\circ} \mathrm{C}$ until analysis.

BDNF concentration was measured spectrophotometrically in samples of plasma and whole blood using ChemiKine ${ }^{\mathrm{TM}}$ BDNF Sandwich ELISA Kit (Chemicon International, Inc., USA) according instruction manual. Each sample was measured in duplicate. Results were expressed as mean $\mathrm{pg}$ BDNF/mg of protein \pm SEM. BDNF concentration in blood cells was calculated as the difference between whole blood and plasma BDNF concentration. Statistical analysis was performed with one-way ANOVA followed by Dunnett posttest. The value of $p$ less than 0.05 was considered to be statistically significant.

Transient MCAO occlusion affected BDNF concentration in circulatory system on several levels. In the normal physiological condition represented by control samples, BDNF concentration in whole blood reached $307 \mathrm{pg} / \mathrm{mg}$ of protein. During ischemia we observed a transient drop at $40 \mathrm{~min}$ (by $33.7 \%$ ) followed by a recovery to control level at the end of the ischemic insult and gradual reduction of whole blood BDNF dropping $38 \%$ below of control value at $90 \mathrm{~min}$ during reperfusion.

In blood cells, BDNF level fluctuation is similar to the whole blood. Ischemia induction led to a decrease in BDNF level from $228.45 \mathrm{pg}$ to $134.8 \mathrm{pg} / \mathrm{mg}$ of protein. After an elevation of BDNF concentration at the end of ischemia $(297.6 \mathrm{pg} / \mathrm{mg}$ of protein), its level started decreasing, reaching less than $20 \%$ of control value at $90 \mathrm{~min}$ of reperfusion. 
On the contrary, plasma level of BDNF started to decrease during ischemia with a minimum at the end of insult (I90) when it was at $44 \%$ ( $34.9 \mathrm{pg} / \mathrm{mg}$ of protein) of sham control concentration ( $78.55 \mathrm{pg} / \mathrm{mg}$ of protein). Reperfusion period led to a subsequent elevation of BDNF approximately to the baseline level before ischemia (Fig. 1A).

In the model of $10 \mathrm{~min}$ global ischemia we did not observe any changes in BDNF blood levels immediately after the ischemic insult. However, notable changes of its concentration during the reperfusion were reported. In whole blood we observed significant decrease of this protein at $40 \mathrm{~min}$ (by about 28\%) up to $90 \mathrm{~min}$ of blood supply restoration. In blood cells, BDNF concentration was reduced to about $75 \%$ of control value $40 \mathrm{~min}$ after the beginning of reperfusion period and, in contrast to MCAO animals, continuously decreased to $50 \%$ of control by $90 \mathrm{~min}$ or reperfusion. Plasma level was not changed during $40 \mathrm{~min}$ of recirculation, but reached a 155\% elevation at 90 min when compared to control (Fig. 1B).

Essential role of BDNF in brain development, physiology and pathology is unquestioned. Moreover, changes in plasma level of BDNF seem to be related to several neurological, mainly neuropsychiatric disorders, such as depression (Shimizu et al. 2003) or bipolar disorder (Machado-Vieira et al. 2007). Literal data confirm variation of brain tissue BDNF also in models of the most common cause of neurological death, brain ischemia (Tsukahara et al. 1994, 1998; Kokaia et al. 1995, 1996). However, there is no clear evidence about its variations in blood.

In our previous work we observed changes of some biochemical parameters in blood in model of global (Kravcukova et al. 2009, 2010) as well as focal ischemia (unpublished data) that are clearly expressed mainly in early period of postischemic recirculation. Based on this we decided to study ischemia impact on blood BDNF during blood supply restriction and early reperfusion and examine its effect on whole blood, plasma and blood cells.

Exogenous additional administration of BDNF seems to be a potential neuroprotector after ischemic attack. It was shown that a direct injection of BDNF into the infarcted brain region (Sakane and Pardridge 1997) or into cerebrospinal fluid by intraventricular administration (Menzies et al. 1993) was neuroprotective. Although BDNF readily crosses the BBB (Pan et al. 1998), there are several reports of insufficient crossing of BDNF molecule from blood to brain tissue after intravenous administration (Zhang and Pardridge 2001, 2006). However, several studies provide an additional important piece of information: blood cells could be a source of BDNF protein.

Fujimura and coworkers (2002) reported that platelets appear to bind, store and release BDNF upon activation at the site of traumatic injury to facilitate the repair of peripheral nerves or other tissues. Moreover, immune cells serve as a source of BDNF. It was observed, that peripheral blood leukocytes isolated from autistic and non-autistic children produce an increased level of this trophic factor after stimulation with lipopolysacharide or phytohemaglutinin ex vivo (Enstrom et al. 2008). Furthermore, an analysis of BDNF production by isolated lymphocyte subsets revealed $\mathrm{T}$ cells as a cellular source of BDNF in a mouse model of allergic inflammation (Braun et al. 1999). BDNF secreted by immune cells (T cells, $\mathrm{B}$ cells, and monocytes) upon antigen stimulation is bioactive, as it supports neuronal survival in vitro. Using an anti-BDNF monoclonal antibody and a polyclonal antiserum, BDNF immunoreactivity was demonstrated in inflammatory infiltrates in the brain of patients with acute disseminated encephalitis and multiple sclerosis (Kerschensteiner et al. 1999). Changes of BDNF blood levels in our experiments not only show blood cells as a possible source of BDNF protein, but also illustrate the interdependence of blood compartments and their relationship to physiological state of an organism. The best examples of this interdependence are: a) a reduction of BDNF level in whole blood and blood cells, but an unchanged or elevated concentration of this growth factor in plasma during focal ischemia, and $b$ ) detected opposite changes of BDNF concentration in blood cells $v s$. plasma at 90 min of reperfusion in both experimental models of transient brain ischemia.

Our data on BDNF blood concentrations in two different models of brain ischemia demonstrate an impact of this injury on circulatory system, causing changes in blood, plasma and cellular levels of BDNF similar to changes described in several other, mainly neuropsychiatric disorders. The results of our experiments contribute to the investigation of the role of BDNF in the pathology of ischemic injury and confirm the importance of blood as a source of this neurotrophic factor.

Acknowledgments. The authors gratefully acknowledge the excellent technical assistance of Dana Jurušová. This study was supported by the Slovak Grant Agencies VEGA 2/0092/12, VEGA 2/0066/12 and APVV-0472-11.

\section{References}

Barde Y. A., Edgar D., Thoenen H. (1982): Purification of a new neurotrophic factor from mammalian brain. EMBO J. 1, 549-553

Beck T., Lindholm D., Castren E., Wree A. (1994): Brain-derived neurotrophic factor protects against ischemic cell damage in rat hippocampus. J. Cereb. Blood Flow Metab. 14, 689-692 http://dx.doi.org/10.1038/jcbfm.1994.86

Binder D. K. (2007): Neurotrophins in the dentate gyrus. Prog. Brain Res. 163, 371-397 http://dx.doi.org/10.1016/S0079-6123(07)63022-2

Binder D. K., Scharfman H. E. (2004): Brain-derived neurotrophic factor. Growth Factors 22, 123-131 http://dx.doi.org/10.1080/08977190410001723308

Braun A., Lommatzsch M., Mannsfeldt A., Neuhaus-Steinmetz U., Fischer A., Schnoy N., Lewin G. R., Renz H. (1999): Cellular sources of enhanced brain-derived neurotrophic factor produc- 
tion in a mouse model of allergic inflammation. Am. J. Respir. Cell. Mol. Biol. 21, 537-546

Enstrom A., Onore C., Tarver A., Hertz-Picciotto I., Hansen R., Croen L., Van de Water J., Ashwood P. (2008): Peripheral blood leukocyte production of BDNF following mitogen stimulation in early onset and regressive autism. Am. J. Biochem. Biotech. 4, 121-129 http://dx.doi.org/10.3844/ajbbsp.2008.121.129

Fujimura H., Altar C. A., Chen R., Nakamura T., Nakahashi T., Kambayashi J., Sun B., Tandon N. N. (2002): Brain-derived neurotrophic factor is stored in human platelets and released by agonist stimulation. Thromb. Haemost. 87, 728-734

Karege F., Schwald M., Cisse M. (2002): Postnatal developmental profile of brain-derived neurotrophic factor in rat brain and platelets. Neurosci. Lett. 328, 261-264 http://dx.doi.org/10.1016/S0304-3940(02)00529-3

Kerschensteiner M., Gallmeier E., Behrens L., Leal V. V., Misgeld T. Klinkert W. E., Kolbeck R., Hoppe E., Oropeza-Wekerle R. L., Bartke I., Stadelmann C., Lassmann H., Wekerle H., Hohlfeld R. (1999): Activated human T cells, B cells, and monocytes produce brain-derived neurotrophic factor in vitro and in inflammatory brain lesions: a neuroprotective role of inflammation? J. Exp. Med. 189, 865-870 http://dx.doi.org/10.1084/jem.189.5.865

Kokaia Z., Zhao Q., Kokaia M., Elmer E., Metsis M., Smith M. L., Siesjo B. K., Lindvall O. (1995): Regulation of brain-derived neurotrophic factor gene expression after transient middle cerebral artery occlusion with and without brain damage. Exp. Neurol. 136, 73-88 http://dx.doi.org/10.1006/exnr.1995.1085

Kokaia Z., Nawa H., Uchino H., Elmer E., Kokaia M., Carnahan J. Smith M. L., Siesjo B. K., Lindvall O. (1996): Regional brainderived neurotrophic factor mRNA and protein levels following transient forebrain ischemia in the rat. Brain Res. Mol. Brain Res. 38, 139-144 http://dx.doi.org/10.1016/0169-328X(96)00002-2

Kravcukova P., Danielisova V., Nemethova M., Burda J., Gottlieb M. (2009): Transient forebrain ischemia impact on lymphocyte DNA damage, glutamic acid level, and SOD activity in blood Cell. Mol. Neurobiol. 29, 887-894 http://dx.doi.org/10.1007/s10571-009-9371-9

Kravcukova P., Danielisova V., Nemethova M., Burda J., Gottlieb M. (2010): Effects of one-day reperfusion after transient forebrain ischemia on circulatory system in the rat. Gen. Physiol. Biophys. 29, 113-121

http://dx.doi.org/10.4149/gpb_2010_02_113

Longa E. Z., Weinstein P. R., Carlson S., Cummins R. (1989): Reversible middle cerebral artery occlusion without craniectomy in rats. Stroke 20, 84-91 http://dx.doi.org/10.1161/01.STR.20.1.84

Machado-Vieira R., Dietrich M. O., Leke R., Cereser V. H., Zanatto V., Kapczinski F., Souza D. O., Portela L. V., Gentil, V. (2007): Decreased plasma brain derived neurotrophic factor levels in unmedicated bipolar patients during manic episode. Biol. Psychiatry 61, 142-144 http://dx.doi.org/10.1016/j.biopsych.2006.03.070

Menzies S. A., Betz A. L., Hoff J. T. (1993): Contributions of ions and albumin to the formation and resolution of ischemic brain edema. J. Neurosurg. 78, 257-266 http://dx.doi.org/10.3171/jns.1993.78.2.0257

Pan W., Banks W. A., Fasold M. B., Bluth J., Kastin A. J. (1998): Transport of brain-derived neurotrophic factor across the blood-brain barrier. Neuropharmacology 37, 1553-1561 http://dx.doi.org/10.1016/S0028-3908(98)00141-5

Pulsinelli W. A., Brierley J. B. (1979): A new model of bilateral hemispheric ischemia in the unanesthetized rat. Stroke 10, 267-272 http://dx.doi.org/10.1161/01.STR.10.3.267

Sakane T., Pardridge W. M. (1997): Carboxyl-directed pegylation of brain-derived neurotrophic factor markedly reduces systemic clearance with minimal loss of biologic activity. Pharm. Res. 14, 1085-1091 http://dx.doi.org/10.1023/A:1012117815460

Schabitz W. R., Schwab S., Spranger M., Hacke W. (1997): Intraventricular brain-derived neurotrophic factor reduces infarct size after focal cerebral ischemia in rats. J. Cereb. Blood Flow Metab. 17, 500-506 http://dx.doi.org/10.1097/00004647-199705000-00003

Schabitz W. R., Sommer C., Zoder W., Kiessling M., Schwaninger M., Schwab S. (2000): Intravenous brain-derived neurotrophic factor reduces infarct size and counterregulates Bax and Bcl-2 expression after temporary focal cerebral ischemia. Stroke 31, 2212-2217 http://dx.doi.org/10.1161/01.STR.31.9.2212

Shimizu E., Hashimoto K., Okamura N., Koike K., Komatsu N., Kumakiri C., Nakazato M., Watanabe H., Shinoda N., Okada S., Iyo M. (2003): Alterations on serum levels of brain-derived neurotrophic factor (BDNF) in depressed patients with or without antidepressants. Biol. Psychiatry 54, 70-75 http://dx.doi.org/10.1016/S0006-3223(03)00181-1

Tsukahara T., Yonekawa Y., Tanaka K., Ohara O., Wantanabe S., Kimura T., Nishijima T., Taniguchi T. (1994): The role of brainderived neurotrophic factor in transient forebrain ischemia in the rat brain. Neurosurgery $34,323-331$ http://dx.doi.org/10.1227/00006123-199402000-00016

Tsukahara T., Iihara K., Hashimoto N., Nishijima T., Taniguchi T. (1998): Increases in levels of brain-derived neurotrophic factor mRNA and its promoters after transient forebrain ischemia in the rat brain. Neurochem. Int. 33, 201-207 http://dx.doi.org/10.1016/S0197-0186(97)00112-5

Yamashita K., Wiessner C., Lindholm D., Thoenen H., Hossmann K. A. (1997): Post-occlusion treatment with BDNF reduces infarct size in a model of permanent occlusion of the middle cerebral artery in rat. Metab. Brain Dis. 12, 271-280 http://dx.doi.org/10.1007/BF02674671

Zhang Y., Pardridge W. M. (2001): Neuroprotection in transient focal brain ischemia after delayed intravenous administration of brain-derived neurotrophic factor conjugated to a blood-brain barrier drug targeting system. Stroke 32, 1378-1384 http://dx.doi.org/10.1161/01.STR.32.6.1378

Zhang Y., Pardridge W. M. (2006): Blood-brain barrier targeting of BDNF improves motor function in rats with middle cerebral artery occlusion. Brain. Res. 1111, 227-229 http://dx.doi.org/10.1016/j.brainres.2006.07.005

Received: February 27, 2012

Final version accepted: July 30, 2012 